\title{
Higher risk of venous thrombosis associated with drospirenone-containing oral contraceptives: a population-based cohort study
}

\author{
Naomi Gronich MD, Idit Lavi MSc, Gad Rennert MD PhD
}

See related commentary by Solymoss at www.cmaj.ca/lookup/doi/10.1503/cmaj.111614

\begin{abstract}
- ABSTRACT
Background: Combined oral contraceptives are a common method of contraception, but they carry a risk of venous and arterial thrombosis. We assessed whether use of drospirenone was associated with an increase in thrombotic risk relative to third-generation combined oral contraceptives.

Methods: Using computerized records of the largest health care provider in Israel, we identified all women aged 12 to 50 years for whom combined oral contraceptives had been dispensed between Jan. 1, 2002, and Dec. 31, 2008. We followed the cohort until 2009. We used Poisson regression models to estimate the crude and adjusted rate ratios for risk factors for venous thrombotic events (specifically deep vein thrombosis and pulmonary embolism) and arterial thromboic events (specifically transient ischemic attack and cerebrovascular accident). We performed multivariable analyses to compare types of contraceptives, with adjustment for the various risk factors.
\end{abstract}

Results: We identified a total of 1017 $(0.24 \%)$ venous and arterial thrombotic events among 431223 use episodes during 819749 woman-years of follow-up (6.33 venous events and 6.10 arterial events per 10000 woman-years). In a multivariable model, use of drospirenone carried an increased risk of venous thrombotic events, relative to both third-generation combined oral contraceptives (rate ratio [RR] 1.43, $95 \%$ confidence interval $[\mathrm{Cl}] 1.15-1.78)$ and second-generation combined oral contraceptives (RR 1.65, 95\% Cl 1.02-2.65). There was no increase in the risk of arterial thrombosis with drospirenone.

Interpretation: Use of drospirenone-containing oral contraceptives was associated with an increased risk of deep vein thrombosis and pulmonary embolism, but not transient ischemic attack or cerebrovascular attack, relative to second- and third-generation combined oral contraceptives.
$\mathrm{O}$ ral hormonal therapy is the preferred method of contraception, especially among young women. In the United States in 2002, 12 million women were using "the pill."1 In a survey of households in Great Britain conducted in 2005 and 2006, onequarter of women aged 16 to 49 years of age were using this form of contraception. ${ }^{2}$ A large variety of combined oral contraceptive preparations are available, differing in terms of estrogen dose and in terms of the dose and type of the progestin component. Among preparations currently in use, the estrogen dose ranges from 15 to $35 \mu \mathrm{g}$, and the progestins are secondgeneration, third-generation or newer. The second-generation progestins (levonorgestrel and norgestrel), which are derivatives of testosterone, have differing degrees of androgenic and estrogenic activities. The structure of these agents was modified to reduce the androgenic activity, thus producing the third-generation progestins (desogestrel, gestodene and norgestimate). Newer progestins are chlormadinone acetate, a derivative of progesterone, and drospirenone, an analogue of the aldosterone antagonist spironolactone having antimineralocorticoid and antiandrogenic activities. Drospirenone is promoted as causing less weight gain and edema than other forms of oral contraceptives, but few well-designed studies have compared the minor adverse effects of these drugs. ${ }^{3}$

The use of oral contraceptives has been reported to confer an increased risk of venous and arterial thrombotic events,,$^{4-7}$ specifically an absolute risk of venous thrombosis of 6.29 per 10000 woman-years, compared with 3.01 per 10000 woman-years among nonusers. ${ }^{8}$ It has
Competing interests: None declared.

This article has been peer reviewed

Correspondence to: Dr. Naomi Gronich, gronichn@clalit.org.il

CMAJ 2011. DOI:10.1503 /cmaj.110463 
long been accepted that there is a dose-response relationship between estrogen and the risk of venous thrombotic events. Reducing the estrogen dose from $50 \mu \mathrm{g}$ to $20-30 \mu \mathrm{g}$ has reduced the risk. ${ }^{9}$ Studies published since the mid-1990s have suggested a greater risk of venous thrombotic events with third-generation oral contraceptives than with second-generation formulations, ${ }^{10-13}$ indicating that the risk is also progestindependent. The pathophysiological mechanism of the risk with different progestins is unknown. A twofold increase in the risk of arterial events (specifically ischemic stroke ${ }^{6,14}$ and myocardial infarction ${ }^{7}$ ) has been observed in case-control studies for users of second-generation pills and possibly also third-generation preparations. ${ }^{7.14}$

Conflicting information is available regarding the risk of venous and arterial thrombotic events associated with drospirenone. An increased risk of venous thromboembolism, relative to secondgeneration pills, has been reported recently, ${ }^{8,15,16}$ whereas two manufacturer-sponsored studies claimed no increase in risk. ${ }^{17,18}$ In the study reported here, we investigated the risk of venous and arterial thrombotic events among users of various oral contraceptives in a large populationbased cohort.

\section{Methods}

This population-based historical cohort study was based on automatically and routinely collected administrative and clinical data in a coded database. As such, approval was not sought from an ethics review board.

\section{Data source}

In Israel, medical care is provided by four notfor-profit health care providers. Every resident of the country may choose to receive his or her medical care from one of these four providers and can switch providers periodically with no penalty. The annual rate of changing providers is about $1 \% .{ }^{19}$ Clalit Health Services is the largest provider. Its enrolment accounts for more than half of the population, with a somewhat older age profile and lower socioeconomic status than the other three providers. ${ }^{19}$ The Clalit clinical database $e^{20,21}$ is a comprehensive database that was established in 1998. It has several components, including a medication database, a chronic diseases database, a primary care database of diagnoses by physician visit, a database of laboratory test results and a database of hospital admissions. The databases are based on a full accounting of relevant data achieved through the centralized and standardized computerization of all Clalit primary care physicians, laboratories, pharmacies, and admissions to and discharges from hospital for those insured. Full computerization of all Clalit providers was achieved in 2002, and our study period therefore started in that year. Among information that was not originally collected but that has been added gradually over time are data on health-related habits such as smoking and health-related markers such as body mass index (which are recorded in the markers database).

\section{Study cohort}

We searched the Clalit medication database for all women for whom at least one combined oral contraceptive prescription had been dispensed between Jan. 1, 2002, and Dec. 31, 2008, and who were between 12 and 50 years of age throughout the study period (i.e., the age range for contraception use and the age limit used in studies of the thromboembolic risk of contraceptives). Each type of combined oral contraceptive used by an individual woman was regarded as a separate use episode. All prescriptions for people insured by Clalit are filled in Clalit pharmacies, which have been centrally computerized since 2002. Variables in the database that were used for this study were the catalogue number of each medication, the date the prescription was first filled, the date it was last filled and the number of prescriptions filled.

We searched the Clalit primary care and hospital databases for diagnoses of deep vein thrombosis (International Classification of Diseases, ninth revision [ICD-9], codes 451.1, 451.83), pulmonary embolism (ICD-9 code 415.1), transient ischemic attack (ICD-9 code 435) and cerebrovascular accident (ICD-9 codes 430-432, 433.01, 433.11, 433.21, 433.31, 433.81, 433.91, $434.01,434.11,434.91,436,438)$ in the study cohort. We excluded women who had any of these diagnoses before starting contraceptive use.

\section{Study outcomes}

We identified first-time diagnoses of thrombotic events, specifically deep vein thrombosis, pulmonary embolism, transient ischemic attack and cerebrovascular accident. We followed the cohort until 2009. We attributed each such event to the last combined oral contraceptive used before the event. Most prescriptions were for a three-month period, and the thromboembolic risk has been reported to disappear within three months after a woman stops using oral contraceptives. ${ }^{13,22}$ Therefore, if an event occurred more than six months since the last combined oral contraceptive was dispensed, we did not attribute it to any contraceptive. We classified deep vein thrombosis and pulmonary embolism diagnosed on the same day 
as pulmonary embolism. We regarded an undetermined diagnosis of either transient ischemic attack or cerebrovascular accident as transient ischemic attack. We calculated the duration of oral contraceptive use from the number of onemonth packages of combined oral contraceptives that were dispensed. The observation time for each woman was the sum of the number of months from beginning of use until six months after the last prescription was dispensed or until a thrombotic event, based on the dates of first and last prescriptions.

\section{Study covariates}

For all women in the study cohort, we searched the Clalit primary care, hospital admission and markers databases for diagnoses of clinical risk factors that are known from the literature to be related to venous and arterial thrombosis, specifically obesity (body mass index > 30), smoking and history of hypertension (ICD-9 401-405), hyperlipidemia (ICD-9 272.0-272.4), diabetes mellitus (ICD-9 250) or cancer (ICD-9 140208). We documented a risk factor if it was diagnosed before the thrombotic event (for women with such an event) or at any time until the end of the study period (for women with no thrombotic event).

\section{Statistical analysis}

Combined oral contraceptives containing norgestrel and levonorgestrel were grouped together as second-generation agents. Formulations containing desogestrel, gestodene or norgestimate were grouped as third-generation products. ${ }^{23,24}$ Combined oral contraceptives containing low-dose gestodene, drospirenone or chlormadinone were analyzed individually. We calculated the crude incidence of venous and arterial thrombotic events in relation to each of the following risk factors: age, diabetes, hyperlipidemia, hypertension, cancer, smoking, obesity and duration of contraceptive use (divided into four groups [quartiles]). We performed multiple imputations using all of the above-listed variables to impute missing data for smoking and obesity. We used Poisson regression analysis, with robust standard errors, to estimate the crude rate ratio (RR) for each risk factor and the adjusted RRs, with $95 \%$ confidence intervals [CIs], for venous and arterial thrombotic events for the contraceptive types. We also ran the model using the negative binomial distribution, for which the shape parameter is a convenient index of overdispersion. The results in these two models were similar. We performed multivariable analyses to compare types of treatment (drospirenone v. third-generation, drospirenone v. second-generation, third-generation v. secondgeneration), with adjustment for other risk factors.

We also performed a secondary analysis to determine if estrogen dosage affected the outcome. Specifically, we used the same model to compare third-generation oral contraceptives containing $20 \mu \mathrm{g}$ ethinylestradiol (combined with desogestrel or gestodene, accounting for $44.4 \%$ of all use episodes in our cohort) with third-generation oral contraceptives containing 30-35 $\mu$ g ethinylestradiol (combined with desogestrel, gestodene or norgestimate, accounting for $29.0 \%$ of all use episodes in our cohort).

\section{Results}

In our study population, a combined oral contraceptive was prescribed at least once to $14 \%$ of women 12-50 years of age and $20 \%$ of women 16-35 years of age. We noted a marked shift in prescribing patterns over the study period, with disappearance of the use of second-generation combined oral contraceptives and a marked

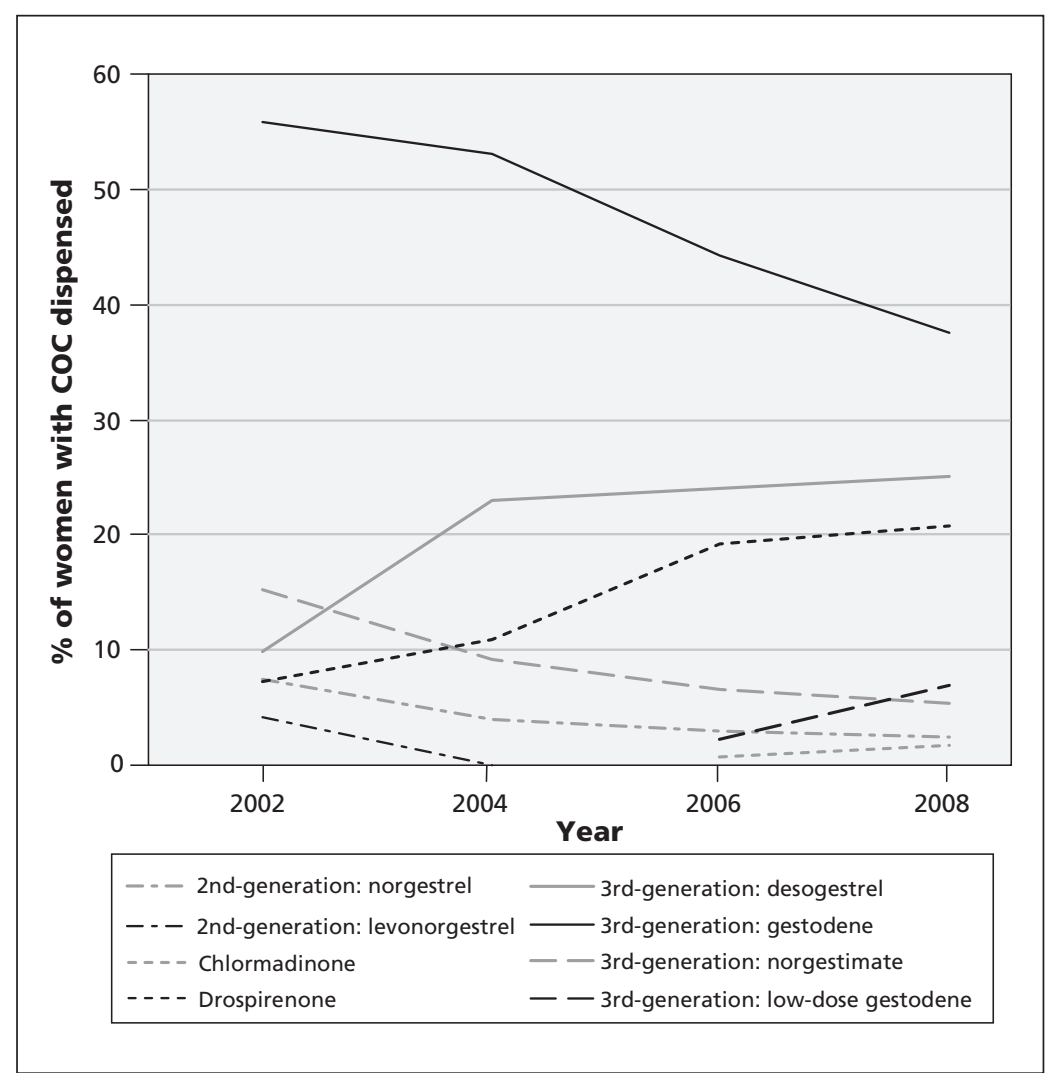

Figure 1: Time trends in the use of various combined oral contraceptives (COCs). In total, $5.0 \%$ of women in the study cohort used second-generation agents ( $4.1 \%$ norgestrel and $0.9 \%$ levonorgestrel), $73.4 \%$ used thirdgeneration agents $(22.7 \%$ desogestrel, $41.6 \%$ gestodene and $9.1 \%$ norgestimate), $3.6 \%$ used the low-dose gestodene-containing agent, $17.1 \%$ used a drospirenone-containing $\mathrm{COC}$, and $0.9 \%$ used a $\mathrm{COC}$ containing chlormadinone acetate. All but one of the contraceptive agents contained 20-30 $\mu \mathrm{g}$ ethinylestradiol as the estrogenic component; the norgestimate-containing COC contained $35 \mu \mathrm{g}$ ethinylestradiol. 
increase in the use of drospirenone-containing combined oral contraceptives in recent years (Figure 1). The numbers of users of low-dose gestodene and chlormadinone were too small to allow their inclusion in the multivariable analysis.

Included in the cohort were 329995 women 12-50 years of age, accounting for a total of 431223 use episodes and 819749 woman-years of follow-up. Characteristics of women using second- and third-generation combined oral contraceptives and drospirenone-containing agents are presented in Table 1. During the study period, 1017 venous and arterial thrombotic events were newly diagnosed ( $0.24 \%$ of all use episodes): 359 cases of deep vein thrombosis $(35.3 \%), 159$ cases of pulmonary embolism (15.6\%), 194 cases of transient ischemic attack $(19.1 \%)$ and 305 cases of cerebrovascular accident $(30.0 \%)$, for overall rates of 6.33 venous events and 6.10 arterial events per 10000 woman-years. In the univariable analysis, hyperlipidemia, hypertension, cancer, obesity and older age were found to be significant risk factors for venous thrombosis (Table 2 ). The risk of arterial thrombotic events was also influenced by diabetes. The risk was highest in the first months of use.

In the multivariable analysis, with adjustment for risk factors associated with thrombotic events,

\begin{tabular}{|c|c|c|c|}
\hline \multirow[b]{2}{*}{ Characteristic } & \multicolumn{3}{|c|}{ Type of oral contraceptive*; \% of use episodest } \\
\hline & $\begin{array}{l}\text { Second- } \\
\text { generation } \\
n=21546\end{array}$ & $\begin{array}{l}\text { Third- } \\
\text { generation } \\
n=316371\end{array}$ & $\begin{array}{l}\text { Drospirenone- } \\
\text { containing } \\
n=73629\end{array}$ \\
\hline Age, yr, mean (SD) & $33(8.4)$ & $27(7.6)$ & $26(7.2)$ \\
\hline \multicolumn{4}{|l|}{ Medical history } \\
\hline Diabetes mellitus & 1.78 & 0.71 & 0.64 \\
\hline Hyperlipidemia & 5.66 & 5.07 & 6.11 \\
\hline Hypertension & 3.30 & 1.40 & 1.10 \\
\hline Cancer & 0.78 & 0.68 & 0.69 \\
\hline \multicolumn{4}{|l|}{ Smoking } \\
\hline Yes & 18.48 & 25.21 & 26.28 \\
\hline No & 73.20 & 62.60 & 60.90 \\
\hline Unknown & 8.40 & 12.20 & 12.80 \\
\hline \multicolumn{4}{|l|}{ Obesity } \\
\hline Yes & 26.44 & 15.32 & 13.41 \\
\hline No & 53.20 & 59.20 & 61.60 \\
\hline Unknown & 20.30 & 25.50 & 25.00 \\
\hline \multicolumn{4}{|c|}{$\begin{array}{l}\text { Note: SD = standard deviation. } \\
{ }^{*} \text { In addition to the use episodes for these three categories of combined oral contraceptives, } \\
\text { there were an additional } 19677 \text { use episodes for low-dose gestodene and chlormadinone, } \\
\text { but the sample sizes were too small to allow analysis. } \\
\text { tUnless stated otherwise. }\end{array}$} \\
\hline
\end{tabular}

the risk of venous thrombotic events was significantly greater among drospirenone users than among users of third-generation combined oral contraceptives (RR 1.43, 95\% CI 1.15-1.78) (Table 3). Drospirenone was also associated with increased risk of venous thrombotic events relative to second-generation combined oral contraceptives (RR 1.65, 1.02-2.65) (Appendix 1, available at www.cmaj.ca/lookup/suppl/doi:10.1503 /cmaj.110463/-/DC1). The difference in risk between second- and third-generation combined oral contraceptives was not statistically significant (RR 1.38, 95\% CI 0.90-2.11) (Appendix 2, available at www.cmaj.ca/lookup/suppl/doi:10.1503 /cmaj.110463/-/DC1). Drospirenone was used by a greater proportion of women during the second half of the study period (Figure 1). The detection of disease improved over the study period because of technologic advancement, such as the use of computed tomography angiography for diagnosis of pulmonary embolism. We therefore performed a sensitivity analysis with calendar year as a variable. This modified analysis did not change the results, which implies that the increased risk associated with drospirenone was not a result of detection bias.

The use of drospirenone was not associated with an increased risk of arterial thrombotic events (transient ischemic attack or cerebrovascular accident), relative to use of second- or third-generation combined oral contraceptives, and use of a third-generation agent was not associated with an increased risk of an arterial event, relative to use of a second-generation agent (Table 3, Appendix 1, Appendix 2).

Restricting our analysis to first-time users (i.e., with data for only the first type of combined oral contraceptive used by each individual woman) yielded similar results but with weaker associations, probably because of smaller numbers of use episodes in each group. In this subgroup, the RR values for venous thrombotic events were 1.30 (95\% CI 0.98-1.72) for the comparison of drospirenone with third-generation agents, 1.67 (95\% CI 0.98-2.86) for the comparison of drospirenone with second-generation agents and 1.52 (95\% CI 0.94-2.46) for the comparison of third-generation with secondgeneration agents. There was no increased risk for arterial events.

In the secondary analysis of estrogen dosage within third-generation pills, there was no difference between formulations with $20 \mu \mathrm{g}$ estrogen and those with 30-35 $\mu \mathrm{g}$ estrogen in terms of venous thrombotic events (RR $0.95,95 \%$ CI 0.77-1.16) or arterial thrombotic events (RR $1.10,95 \%$ CI $0.90-1.34)$. 


\section{Interpretation}

Use of drospirenone-containing combined oral contraceptives was associated with a significantly increased risk of venous thrombotic events (deep vein thrombosis and pulmonary embolism) but not arterial thrombotic events (transient ischemic attack and cerebrovascular accident), relative to use of second- or thirdgeneration combined oral contraceptives. Independent risk factors for venous thrombotic events in drospirenone users included older age, obesity and history of cancer. The risk was highest in the first four months of use.

Venous thromboembolism is a welldocumented adverse event occurring with use of oral contraceptives. ${ }^{4,13}$ Following the publication of case studies of thrombotic events in drospirenone users, this risk was studied in two manufacturer-sponsored studies. The first of these was the European Active Surveillance Study, ${ }^{17}$ which had 58674 women and 142475 woman-years of follow-up, with power sufficient to exclude only a twofold or higher risk of

Table 2: Risk factors associated with venous and arterial thrombotic events among users of combined oral contraceptives

\begin{tabular}{|c|c|c|c|c|c|}
\hline \multirow[b]{2}{*}{ Risk factor } & \multirow[b]{2}{*}{$\begin{array}{l}\text { Woman- } \\
\text { years* }\end{array}$} & \multicolumn{2}{|c|}{ DVT and PE } & \multicolumn{2}{|c|}{ TIA and CVA } \\
\hline & & $\begin{array}{l}\text { No. (rate per } 10000 \\
\text { woman-years) }\end{array}$ & $\operatorname{RR}(95 \% \mathrm{Cl})$ & $\begin{array}{l}\text { No. (rate per } 10000 \\
\text { woman-years) }\end{array}$ & $\mathrm{RR}(95 \% \mathrm{Cl})$ \\
\hline \multicolumn{6}{|l|}{ Age, yr } \\
\hline $12-19$ & 97161 & $(3.50)$ & Reference & $(2.37)$ & Reference \\
\hline $20-24$ & 307850 & $(4.52)$ & $1.29 \quad(0.89-1.88)$ & (3.25) & $1.37 \quad(1.06-1.78)$ \\
\hline $30-34$ & 101578 & $73 \quad(7.19)$ & $2.06 \quad(1.37-3.09)$ & $78 \quad(7.68)$ & $3.25 \quad(2.48-4.25)$ \\
\hline $35-39$ & 63020 & $70 \quad(11.11)$ & $3.18 \quad(2.11-4.79)$ & $84 \quad(13.33)$ & $5.64 \quad(4.32-7.36)$ \\
\hline $40-44$ & 39549 & 62 (15.68) & $4.49 \quad(2.96-6.83)$ & $72 \quad(18.21)$ & $7.71 \quad(5.88-10.10)$ \\
\hline $45-50$ & 17016 & $25 \quad(14.69)$ & $4.22 \quad(2.52-7.07)$ & $58 \quad(34.09)$ & $14.41 \quad(10.91-19.05)$ \\
\hline \multicolumn{6}{|c|}{ Diabetes mellitus } \\
\hline No & 758616 & $466 \quad(6.14)$ & Reference & $437 \quad(5.76)$ & Reference \\
\hline Yes & 61133 & $52 \quad(8.51)$ & $1.39 \quad(1.04-1.85)$ & 62 (10.14) & $1.76 \quad(1.51-2.06)$ \\
\hline \multicolumn{6}{|c|}{ Hypertension } \\
\hline No & 804878 & $498 \quad(6.19)$ & Reference & $453 \quad(5.63)$ & Reference \\
\hline Yes & 14871 & $20 \quad(13.45)$ & $2.19 \quad(1.40-3.42)$ & $46 \quad(30.93)$ & $5.50 \quad(4.62-6.56)$ \\
\hline \multicolumn{6}{|l|}{ Cancer } \\
\hline No & 813367 & $501 \quad(6.16)$ & Reference & $491 \quad(6.04)$ & Reference \\
\hline Yes & 6382 & 17 (26.64) & $4.33 \quad(2.67-7.01)$ & $8 \quad(12.54)$ & $(1.39-3.12)$ \\
\hline \multicolumn{6}{|l|}{ Smoking } \\
\hline$\leq 2$ & 75224 & 103 (13.69) & Reference & $97 \quad(12.89)$ & Reference \\
\hline $3-4$ & 68795 & $75 \quad(10.90)$ & $0.80 \quad(0.59-1.07)$ & $83 \quad(12.06)$ & $(0.79-1.11)$ \\
\hline $5-13$ & 211942 & $141 \quad(6.65)$ & $0.49 \quad(0.38-0.63)$ & $154 \quad(7.27)$ & $(0.49-0.65)$ \\
\hline$\geq 14$ & 463788 & $199 \quad(4.29)$ & $0.31 \quad(0.25-0.40)$ & (3.56) & $0.28 \quad(0.24-0.32)$ \\
\hline
\end{tabular}


venous thromboembolism. This study showed noninferiority of drospirenone compared with levonorgestrel and other oral contraceptives. The second study ${ }^{18}$ involved 22429 women initiating drospirenone use (with 14081 woman-years of follow-up) and 44858 women initiating use of "other oral contraceptives" (with 22575 womanyears of follow-up), but again the cohort was too small to observe a difference. In 2009, the Danish national follow-up study ${ }^{8}$ and the MEGA (Multiple Environmental and Genetic Assessment of risk factors for venous thrombosis) case-control study ${ }^{25}$ showed that drospirenone and third-generation oral contraceptives carried increased risks of venous thromboembolism, when compared with second-generation oral contraceptives; however, drospirenone was not directly compared with the third-generation contraceptives. Two recent case-control studies identified an increased risk of venous thromboembolism with drospirenone, relative to second-generation levonorgestrel. ${ }^{15,16}$ The exact mechanism by which drospirenone might increase the risk of venous thrombotic events is unknown. An increased prothrombotic effect was demonstrated for both drospirenone and thirdgeneration pills, compared with secondgeneration pills. ${ }^{26}$

\begin{tabular}{|c|c|c|}
\hline \multirow[b]{2}{*}{ Variable } & \multicolumn{2}{|c|}{ Type of event; adjusted RR* $(95 \% \mathrm{Cl})$} \\
\hline & DVT and PE & TIA and CVA \\
\hline $\begin{array}{l}\text { Third-generation oral } \\
\text { contraceptivet }\end{array}$ & Reference & Reference \\
\hline $\begin{array}{l}\text { Drospirenone-containing } \\
\text { oral contraceptive } \neq\end{array}$ & $1.43(1.15-1.78)$ & $0.97 \quad(0.74-1.26)$ \\
\hline Age, per year & $1.05(1.04-1.06)$ & $1.08(1.07-1.10)$ \\
\hline Diabetes mellitus & $0.40(0.13-1.24)$ & $1.42(0.78-2.59)$ \\
\hline Hyperlipidemia & $1.26(0.94-1.69)$ & $1.20(0.88-1.64)$ \\
\hline Hypertension & $1.42(0.90-2.26)$ & $2.16(1.49-3.13)$ \\
\hline Cancer & $3.37(2.01-5.67)$ & $1.39(0.65-2.94)$ \\
\hline Smoking & $0.99(0.80-1.23)$ & $1.19(0.97-1.46)$ \\
\hline Obesity & $1.72(1.39-2.12)$ & $1.47(1.19-1.83)$ \\
\hline Duration of use, per month & $0.98(0.97-0.98)$ & $0.97 \quad(0.96-0.98)$ \\
\hline \multicolumn{3}{|c|}{ 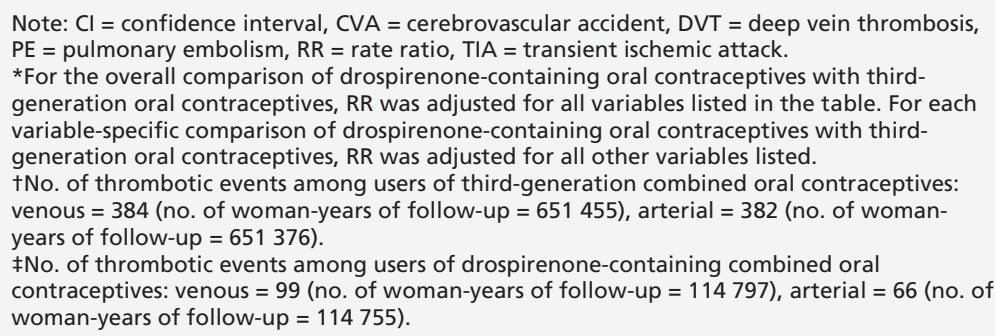 } \\
\hline
\end{tabular}

We did not observe any increased risk of arterial events with drospirenone relative to second- or third-generation combined oral contraceptives, and no such increased risk has been found in comparisons of third-generation pills with second-generation formulations..$^{7,14}$ Drospirenone, as an aldosterone antagonist, also decreases the blood pressure slightly, ${ }^{27}$ which might balance other factors favouring arterial thrombosis. In case-control studies, smoking was found to be a risk factor for arterial events, but not for venous thrombotic events. . $^{6,13,1,14,16}$

We found that women were most vulnerable during the first months of using combined oral contraceptives. A similar pattern was previously demonstrated for venous event ${ }^{25}$ but not for arterial events. ${ }^{6}$ The reason for this temporal variation in risk has not been studied. Perhaps a relatively short period is enough to expose susceptible women and to facilitate the thrombotic process.

\section{Limitations}

Our study had several limitations. There was a possibility of confounding by indication if physicians preferred to prescribe drospirenonecontaining contraceptives to women with a presumed higher risk of venous thromboembolism. We adjusted for most of the known clinical risk factors for venous thromboembolism that might have led to a change in prescription, but we did not have information about family history of this condition. Restricting our analysis to first-time users, to reduce indication bias (as was suggested by an earlier study ${ }^{28}$ ), did not change the results.

With the database system used for this study, we could not verify diagnoses by examining imaging data. Overdiagnosis might have occurred among users of oral contraceptives but presumably did not occur more often with certain types of pills. Another limitation was our inability to evaluate hospital admissions or acute illnesses as predisposing factors; again, however, a thrombotic event resulting from immobilization would probably not occur more often with a specific kind of combined oral contraceptive. Finally, we could not compare minor adverse effects or advantages between the preparations that we studied.

\section{Conclusion}

Most of the available information about the risks of venous and arterial thrombotic events in users of oral contraceptives comes from case-control studies. Venous and arterial events are typically described in separate cohorts. Our cohort of women from a large, unselected population, identified through computerized records, pro- 
vides insight into risk factors for thrombotic events, as well as an opportunity to compare the risks of thrombotic events between different contraceptive preparations. With the increasing use of drospirenone-containing contraceptives, it is important to raise awareness of the increased, albeit small, risk of venous thromboembolism relative to third-generation pills, especially among those who are older or obese. Further research should explore the pathophysiologic mechanism of the risk of venous thromboembolism with drospirenone.

\section{References}

1. Mosher WD, Martinez GM, Chandra A, et al. Use of contraception and use of family planning services in the United States: 1982-2002. Adv Data 2004;(350):1-36.

2. Taylor T, Keyse L, Bryant A. Contraception and sexual health, 2005/06. London (UK): National Statistics; 2006.

3. Lawrie TA, Helmerhorst FM, Maitra NK, et al. Types of progestogens in combined oral contraception: effectiveness and side-effects. Cochrane Database Syst Rev 2011;(5):CD004861.

4. Vandenbroucke JP, Rosing J, Bloemenkamp KW, et al. Oral contraceptives and the risk of venous thrombosis. $N$ Engl J Med 2001:344:1527-35.

5. Gomes MP, Deitcher SR. Risk of venous thromboembolic disease associated with hormonal contraceptives and hormone replacement therapy: a clinical review. Arch Intern Med 2004; 164:1965-76

6. Ischaemic stroke and combined oral contraceptives: results of an international, multicentre, case-control study. WHO Collaborative Study of Cardiovascular Disease and Steroid Hormone Contraception. Lancet 1996;348:498-505.

7. Tanis BC, van den Bosch MA, Kemmeren JM, et al. Oral contraceptives and the risk of myocardial infarction. $N$ Engl J Med 2001;345:1787-93.

8. Lidegaard $\varnothing$, Løkkegaard E, Svendsen AL, et al. Hormonal contraception and risk of venous thromboembolism: national follow-up study. BMJ 2009;339:b2890.

9. Gerstman BB, Piper JM, Tomita DK, et al. Oral contraceptive estrogen dose and the risk of deep venous thromboembolic disease. Am J Epidemiol 1991;133:32-7.

10. Jick H, Jick SS, Gurewich V, et al. Risk of idiopathic cardiovascular death and nonfatal venous thromboembolism in women using oral contraceptives with differing progestagen components. Lancet 1995;346:1589-93.

11. Effect of different progestagens in low oestrogen oral contraceptives on venous thromboembolic disease. World Health Organization Collaborative Study of Cardiovascular Disease and Steroid Hormone Contraception. Lancet 1995;346:1582-8.

12. Spitzer WO, Lewis MA, Heinemann LA, et al. Third generation oral contraceptives and risk of venous thromboembolic disorders: an international case-control study. Transnational Research Group on Oral Contraceptives and the Health of Young Women. BMJ 1996;312:83-8.

13. Venous thromboembolic disease and combined oral contraceptives: results of international multicentre case-control study. World Health Organization Collaborative Study of Cardiovascular Disease and Steroid Hormone Contraception. Lancet 1995;346:1575-82.

14. Kemmeren JM, Tanis BC, van den Bosch MA, et al. Risk of Arterial Thrombosis in Relation to Oral Contraceptives (RATIO) study: oral contraceptives and the risk of ischemic stroke. Stroke 2002;33:1202-8.
15. Jick SS, Hernandez RK. Risk of non-fatal venous thromboembolism in women using oral contraceptives containing drospirenone compared with women using oral contraceptives containing levonorgestrel: case-control study using United States claims data. BMJ 2011;342:d2151.

16. Parkin L, Sharples K, Hernandez RK, et al. Risk of venous thromboembolism in users of oral contraceptives containing drospirenone or levonorgestrel: nested case-control study based on UK General Practice Research Database. BMJ 2011;342: d2139.

17. Dinger JC, Heinemann LA, Kühl-Habich D. The safety of a drospirenone-containing oral contraceptive: final results from the European Active Surveillance Study on oral contraceptives based on 142475 women-years of observation. Contraception 2007;75:344-54

18. Seeger JD, Loughlin J, Eng PM, et al. Risk of thromboembolism in women taking ethinylestradiol/drospirenone and other oral contraceptives. Obstet Gynecol 2007;110:587-93.

19. Bendelac J. Membership in sick funds, 2010. Report 233. Jerusalem (Israel): National Insurance Institute of Israel; 2011. $112 \mathrm{p}$.

20. Matok I, Gorodischer R, Koren G, et al. The safety of metoclopramide use in the first trimester of pregnancy. $N$ Engl $J$ Med 2009;360:2528-35.

21. Meyerovitch J, Rotman-Pikielny P, Sherf M, et al. Serum thyrotropin measurements in the community: five-year follow-up in a large network of primary care physicians. Arch Intern Med 2007; 167:1533-8.

22. Rosenberg L, Palmer JR, Rao RS, et al. Low-dose oral contraceptive use and the risk of myocardial infarction. Arch Intern Med 2001;161:1065-70.

23. Goldman MB, Hatch MC. Contraception. In: Women and health San Diego (CA): Academic Press; 2000. p. 138-59.

24. Hatcher RA, Trussell J, Nelson AL, et al. Contraceptive technology. 19th ed. New York (NY): Ardent Media; 2007.

25. van Hylckama Vlieg A, Helmerhorst FM, Vandenbroucke JP, et al. The venous thrombotic risk of oral contraceptives, effects of oestrogen dose and progestogen type: results of the MEGA case-control study. BMJ 2009;339:b2921.

26. van Vliet HA, Winkel TA, Noort I, et al. Prothrombotic changes in users of combined oral contraceptives containing drospirenone and cyproterone acetate. J Thromb Haemost 2004;2:2060-2.

27. Junge W, El-Samalouti V, Gerlinger C, et al. Effects of menopausal hormone therapy on hemostatic parameters, blood pressure, and body weight: open-label comparison of randomized treatment with estradiol plus drospirenone versus estradiol plus norethisterone acetate. Eur J Obstet Gynecol Reprod Biol 2009; 147:195-200.

28. Suissa S, Blais L, Spitzer WO, et al. First-time use of newer oral contraceptives and the risk of venous thromboembolism. Contraception 1997;56:141-6.

Affiliations: From the Department of Community Medicine and Epidemiology (Gronich, Lavi, Rennert), Carmel Medical Center and Bruce Rappaport Faculty of Medicine, TechnionIsrael Institute of Technology, Haifa; and the Department of Epidemiology and Disease Prevention (Rennert), Office of Chief Physician, Clalit Health Services Headquarters, Tel Aviv, Israel

Contributors: Naomi Gronich, Idit Lavi and Gad Rennert contributed to the conception and design of the study and to the analysis and interpretation of data. Naomi Gronich and Idit Lavi collected the data and drafted the article. Gad Rennert revised it critically for important intellectual content. All authors approved the final version of the manuscript submitted for publication.

Funding: No external funding was received for this study. 